\title{
Green IS Management Framework Corroboration and Verification: Explicating the Enabling Capabilities of Green IS
}

\author{
Grant R. Howard \\ Sam Lubbe \\ Magda Huisman \\ Rembrandt Klopper
}

\begin{abstract}
The first objective of the paper is to demonstrate the quantitative corroboration of the Green Information Systems (Green IS) management framework, which comprises the enabling capabilities of Green IS, the moderating concepts, and their relationships to environmental sustainability. The second objective is to demonstrate the framework's verification using the focus group method and member checking. The achievement of these objectives establishes that the framework successfully captured the essential Green IS concepts and interrelationships to be relevant for environmental sustainability, that it was credible, relevant, and an original contribution to the academic body of knowledge. The research was empirical, confirmatory, quantitative, and qualitative. The study provides research design insights by detailing research design choices and rationale. The framework presents verified and salient management focal points for environmental sustainability in the South African banking sector.
\end{abstract}

Keywords: Content analysis, correspondence analysis, environmental sustainability, Green computing, Green Information Systems (Green IS), Green Information Technology (Green IT), framework, focus group, member checking. 


\section{Introduction, Background and Context}

People are entirely dependent on the Earth's natural resources for their existence. Nevertheless, human activities are degrading and depleting these resources, and this threatens human well-being and possibly long-term human survival (Elliot 2011; Melville 2010; Watson, Boudreau \& Chen 2010; UNEP 2010). In reaction, the concept of environmental sustainability confronts this problem. Environmental sustainability aims to maintain the environment in order to support human well-being and life into the far future (Goodland 1995).

Specifically, there are four degrees of environmental sustainability, namely very weak, weak, strong, and very strong (Goodland \& Daly 1996; Ekins, Simon, Deutsch, Folke \& De Groot 2003). Very weak and very strong environmental sustainability are not feasible, and weak promotes sustained capitalism and business at the expense of the environment (Laine 2010; Manzini, Islas \& Macías 2011; Jenkin, Webster \& McShane 2011). However, strong environmental sustainability demonstrates the non-substitutability of manufactured capital for all natural capital (Dietz \& Neumayer 2007) and its necessity is substantiated by the indisputable scientific evidence on environmental resource depletion and degradation.

The unit of analysis and focus is the organisation. Organisations are the drivers of the world's economies (Watson \& Boudreau 2011) and are responsible for considerable natural resource degradation and depletion (Perrow 1997; Hoffman 2010). Nonetheless, organisations present significant opportunities for environmental sustainability (The Climate Group 2008). In particular, banking organisations offer an opportunity, through their widespread investment and financing activities, to address extensive environmental resource degradation and depletion (Allenby, Compton \& Richards 2001; EP 2012).

Importantly, Information Systems (IS) have been prominent in transforming the world's organisations (Pitt, Parent, Junglas, Chan \& Spyropoulou 2011; Kuo 2010; Mithas, Ramasubbu \& Sambamurthy 2011; Besson \& Rowe 2012) and have fulfilled a critical enabling role (Tambe \& Hitt 2012; Chen 2012; Aral, Brynjolfsson \& van Alstyne 2012; Roberts \& Grover 2012; Dao, Langella \& Carbo 2011). Thus, IS present an essential mechanism for addressing environmental resource degradation and depletion within organisations. However, prior research has not exposed the enabling and transforming capabilities of Green IS for environmental sustainability (Meacham, Toms, Green Jr \& Bhadauria 2013; Howard \& Lubbe 2012). 
Subsequently, an empirical Green IS management framework was developed using a grounded theory approach in the South African (SA) banking sector. Thereafter, the framework was corroborated and verified, this is the focus of the paper.

\section{Research Problem, Objectives, and Questions}

The paper has two objectives. The first objective is to demonstrate the quantitative corroboration of the Green Information Systems (Green IS) management framework, which comprises the enabling capabilities of Green IS, the moderating concepts, and their relationships to environmental sustainability. The second objective is to demonstrate the framework's verification using the focus group method and member checking. These objectives address the problem of an unverified framework and their achievement shows that the framework was credible, and relevant.

The achievement of the first objective answers the first research question: quantitatively, how do the enabling capabilities of Green IS, the moderating concepts, and environmental sustainability relate to one another? The achievement of the second objective answers the second research question: according to experts, does the framework successfully capture the essential Green IS concepts and interrelationships to be relevant for environmental sustainability?

\section{Literature Review}

There are numerous terminology debates concerning the definitions and boundaries of IS and Information Technology (IT). Nonetheless, the paper adheres to the view that IT is a component of IS (Watson, Boudreau, Chen \& Huber 2008). Thus, IT focuses on the technological systems comprising physical devices and associated software that are used to retrieve, transmit, process, and store data and information (Watson et al. 2008). In comparison, IS are systems comprising social systems that include people and processes and the aforementioned IT in support of individual, organisational, or societal goals (Watson, Boudreau \& Chen 2010; Lee 2004). Consequently, Green IT involves environmental sustainability throughout the IT lifecycle (Molla, Pittayachawan \& Corbitt 2009; Murugesan 2008) focusing on energy efficiency maximisation and e-waste minimisation (Watson et al. 2008). In comparison, Green IS are specialised IS that address the problem of 
environmental resource depletion and degradation attributable to all organisational activities (Watson et al. 2008).

Green IS provide the information processing, knowledge, and response capabilities for organisations relating to the environment and facilitate environmental decision-making based on complex and large-scale environmental information (Holmström, Mathiassen, Sandberg \& Wimelius 2010). Green IS are appropriate for addressing the substantial cognitive load of environmental information and help to embed sustainability into an organisation's operations and culture (Volkoff, Bertels \& Papania 2011). Green IS facilitate sustainability by the provision of accurate, timely, and useful information concerning the flows of energy, materials, and water, and the corresponding monetary effects on costs, savings, and earnings (Curry, Hasan, ul Hassan, Herstand \& O'Riain 2011). The generation of digital data by Green IS motivates sustainability changes that produce operational efficiencies and improvements, maintenance cost and emission reductions, and improved profitability (Watson, Boudreau, Li \& Levis 2010). Particularly, Green IS promote the measurement of complex environmental measures in order to reduce risk and uncertainty in environmental sustainability decisionmaking (Watson, Corbett, Boudreau \& Webster 2012).

\section{Methodology}

\section{Content and Correspondence Analysis}

In order to corroborate the framework, which was initially developed using a grounded theory approach in the SA banking sector, content and corresponddence analysis was conducted. Content analysis is an approach to the analysis of texts and documents, including interview transcripts, and aims to objectively quantify the content in terms of predetermined categories in a replicable and systematic way (Bryman \& Bell 2011; Ceci \& Iubatti 2012). It is objective because it is transparent in its procedures for assigning data to categories, it is systematic because the rules are applied in a consistent manner, and it is replicable because any researcher can employ the same rules to achieve the same results. These aspects of content analysis mitigate personal researcher bias.

The term 'correspondence analysis' is a direct translation of its original French term analyses des correspondances, which means a system of associations between sets of variables, with the objective of facilitating interpretation with a global view of the data (Lee 1996). Correspondence analysis 
complements content analysis by providing a perceptual map of the multivariate data in order to substantiate findings, corroborate theoretical interpretations, and facilitate deeper understanding (Remenyi 1992). It provides a statistical visualisation of the associations within a two-way contingency table (Lee 1996). Importantly, this analysis is suited to social science research, which is consistent with IS research, and especially appropriate for categorical data in a contingency table (Greenacre \& Lewi 2009; Greenacre 2006; Phillips 1995). The only data requirement for correspondence analysis is a two-way contingency table with non-negative data elements, such as a contingency table produced during content analysis (Nagpaul 1999).

Correspondence analysis provides an appropriate means for exposing systematic relationships between variables. It greatly simplifies complex data while accounting for all information in the data (Nagpaul 1999; Phillips 1995) by reducing the dimensionality of a data matrix to produce a graphic in a low dimensional subspace, usually a two-dimensional subspace or two axes (Nenadic \& Greenacre 2007). Correspondence analysis illustrates the nature of the relationships between variables, and not just that there are relationships (Nagpaul 1999).

\section{Focus Group}

In order to verify the framework a focus group was conducted with expert informants. Such a focus group provides conclusive evidence from knowledgeable and professional practitioners in the field for verification (Rosemann \& Vessey 2008). The focus group approach is consistent with the purpose of interpretivism and appropriate for IS research (Tremblay, Hevner \& Berndt 2010) and for testing frameworks (O'hEocha, Wang \& Conboy 2012; Rosemann \& Vessey 2008; Soni \& Kodali 2013).

To locate experts, Internet searches were done for SA-based sustainability experts, leaders, and management. Importantly, no experts that had already participated in the study were invited to the focus group. The necessary criteria for an expert were relevant and expert knowledge and experience with regards to environmental sustainability and related IS, time, willingness, capacity to participate, and effective communication skills (Carey \& Asbury 2012).

During the focus group, the lead researcher did not participate in the discussions in any way, either verbally or non-verbally. He was present only 
to do the necessary administration, personally thank the participants, and perform an observer and note-taker role. The session was moderated entirely by a university lecturer who was not involved in any type of sustainability research; this prevented any content bias on the part of the moderator. The focus group took place in a private corporate boardroom located in Johannesburg, SA during February 2014.

The expert status of the nine focus group participants was justified in terms of formal qualifications and experience. In terms of highest relevant qualification, three had PhDs, two had master's degrees, two had SA professsional chartered accountancy registrations, one had a postgraduate honours degree, and one did not provide qualification information. All had between 5 and 20 years of direct relevant experience, with an average of over 9 years.

The direct relevant experience was evident in the participants' occupations, namely a recently retired company partner and director and leader for Integrated Reporting, a sustainability professional and sustainability reporting standard council member, an IS research professor not related to the study in any way, a consultant in sustainability and Integrated Reporting, a consultant and advisor to multinational and domestic companies on legal, tax and sustainability compliance, governance and risk management, a consultant and author on sustainability and Integrated Reporting, an environmental specialist who was also a portfolio planner and environmental analyst, a sustainability consultant, who was also an adjunct faculty member at a leading business school and advisory committee member on a United Nations sustainability body, and a consultant evaluating and promoting the role of business in global sustainable development, who was also a researcher, writer, and strategy consultant.

In addition, the participants were from relevant SA organisations, namely a large and prominent auditing firm, a large financial services company, a large university, a large bank, a consulting firm providing a variety of environmental legal services, a leading accountancy body, a government banking organisation, an independent consultant, and a sustainability strategy and management systems company.

\section{Member Checking}

Member checking is considered one of the most important provisions for a study's credibility and also provides verification of the researcher's emerging theories and inferences (Shenton 2004). Member checking involves presenting 
the research findings to key informants to determine whether they can recognise their experiences in the findings (Krefting 1991). The member checking took place during March 2014.

The key informants for the member checking were the original key informants or interviewees from the initial framework development (Howard, 2014). During the initial framework development there was one key informant from each sampled organisation except the SA sustainability software vendor that had two key informants. The number of people managing what is termed sustainability in these organisations was small. Thus, a single high-level key informant from each organisation was appropriate. All the key informants were specialist management, senior level management, or directors who had the necessary strategic, management, and operational sustainability knowledge. The corresponding sampled organisations were the five largest SA corporate banks, a large SA retail bank, a SA banking industry body, and a leading SA sustainability software vendor.

These sampled organisations made up $100 \%$ of the corporate banks in the JSE's top 100 companies list by market capitalisation (the JSE is SA's Johannesburg Stock Exchange and it is the African continent's premier stock exchange) or $70 \%$ of all the banking organisations, not just corporate banks, in that list or $58 \%$ of all the SA registered banking organisations that are under SA control, not just corporate banks and not just those on that list. This represented a significant proportion of the SA banking sector and of the influence of the sector on the SA economy and natural environment. Of all the original interviewees, only one of the corporate banks and the industry body did not provide feedback due to work pressures. Furthermore, an additional corporate sustainability software vendor was approached for member checking because of its particular prominence in the SA market relating to sustainability software.

\section{Research Findings \\ Initial Framework}

The initial framework was developed using a grounded theory approach in the SA banking sector. A high-level concept that emerged from the data was environmental sustainability transformation. The SA banks were undergoing a process of transformation relating to environmental sustainability and demonstrated this, albeit to varying degrees. This transformation related to 
each bank's own or internal transformation and to the transformation of other organisations throughout the economy or external transformation as a result of financing and investment by the banks. The dominant type of transformation was a combination of economic, environmental, and social, where the environmental competed against both social and economic sustainability, of which economic had the highest priority. This equated to a weak form of environmental sustainability. Nonetheless, there was also evidence of a strong form of environmental sustainability transformation although to a far lesser degree.

Another high-level concept that emerged from the data was the enabling capability of Green IS, which is the intangible characteristic of Green IS that provides the means for environmental sustainability. Significantly, there was only evidence of the enabling capability of Green IS and no evidence of the transforming capability of Green IS, which is the intangible characteristic of Green IS that drives organisational transformation for environmental sustainability. The enabling capability of Green IS had six definite aspects and each was a manifestation or evidence of the enabling capability of Green IS or a Green IS enabled management function. These aspects were business process efficiencies, environmental data management, environmental analysis, environmental information disclosure, carbon footprint management, and environmental risk management.

The first aspect, business process efficiencies, was IS that were not explicitly designed for environmental sustainability purposes, this aspect was implicitly Green IS because its implementations affected environmental sustainability, e.g. IS-enabled automation of paper-based processes resulting in decreased resource waste and/or usage. The second aspect, environmental data management, was Green IS that enabled the management of organisations' environmental data, e.g. kilowatt-hours, which were signifycantly different to the organisations' financial and transactional data. The third aspect, environmental analysis, was Green IS that enabled analysis of the effect of business activities on the environment and exposed meaningful patterns, e.g. environmental dashboards. The fourth aspect, environmental information disclosure, was Green IS that enabled the disclosure of an organisation's environmental information, e.g. specialised environmental reports.

The fifth aspect, carbon footprint management, was Green IS that enabled the management of an organisation's greenhouse gas (GHG) emissions and was primarily internal in focus. The sixth aspect, environmental risk management, was Green IS that enabled the management of the risks to a 
bank arising from financing and investment activities and was primarily external in focus, e.g. credit risk and reputational risk. In addition, business process efficiencies, environmental data management, environmental analysis, and environmental information disclosure were considered lower level aspects, while carbon footprint management and environmental risk management were regarded as higher-level aspects because, in many instances, these higher-level aspects subsumed the lower level aspects.

Importantly, there were three concepts that moderated the relationship between the enabling capability of Green IS and environmental sustainability transformation, namely Green IS integration, environmental data quality, and environmental-financial translation (Howard 2014). It was evident that a lack of integration of Green IS into organisational systems and processes resulted in the exclusion of environmental considerations, which negatively affected environmental sustainability transformation. It was also evident that environmental data quality had a substantial effect on environmental sustainability transformation. In addition, evidence showed that without environmentalfinancial translation, the transformation could not be controlled or managed, which had a material effect on environmental sustainability transformation.

\section{Content and Correspondence Analysis}

The content analysis investigated the intensity of the context units contained in the interview transcripts (Remenyi 1992) of the original key informants or interviewees from the initial framework development. Content analysis can be performed on various types of context units such as specific words, sentences, characters, or concepts (Ceci \& Iubatti 2012). The context unit in this study was the concept. More specifically, it was the concepts that emerged during the initial framework development because these concepts were the concepts of interest to the research and their analysis provided an answer to the first research question. Thus, the 208 pages of typed interview transcripts produced during the initial framework development were content analysed in terms of the emergent concepts (Bhattacherjee \& Premkumar 2004). The content analysis produced a concept-count matrix or concept contingency table as shown in Table 1 below.

Table 1: Concept contingency table - cf. overleaf. 
Grant R. Howard, Sam Lubbe, Magda Huisman \& Rembrandt Klopper

\begin{tabular}{|c|c|c|c|c|c|c|}
\hline 莺 & $\tilde{\sim}$ & $N$ & $\vec{\sim}$ & $\approx$ & $\stackrel{2}{ }$ & $\widehat{\sigma}$ \\
\hline 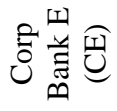 & $n$ & - & 0 & 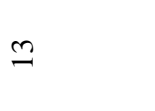 & $N$ & 0 \\
\hline 记 & nె & 0 & 0 & $r$ & - & 0 \\
\hline 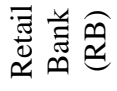 & $\ddot{n}$ & 0 & ㄷ & ㅇ & $r$ & in \\
\hline $\begin{array}{l}\overrightarrow{0} \\
0 \\
0 \\
0\end{array}$ & $\bar{m}$ & 0 & 0 & $m$ & - & 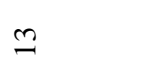 \\
\hline 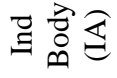 & $m$ & 0 & 0 & 0 & - & $\nabla$ \\
\hline 记层 & $\stackrel{2}{2}$ & 0 & 0 & 0 & 0 & 0 \\
\hline 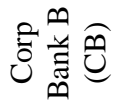 & $\stackrel{2}{ }$ & 0 & - & $\underline{0}$ & $N$ & $a$ \\
\hline 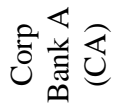 & $\bumpeq$ & - & $m$ & $\stackrel{\infty}{-1}$ & $n$ & 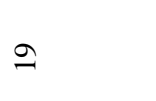 \\
\hline 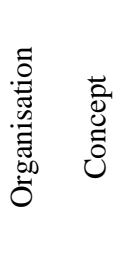 & 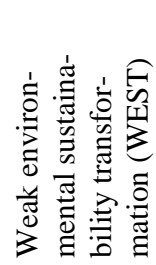 & 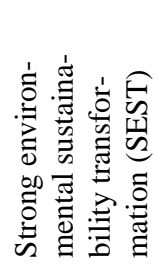 & 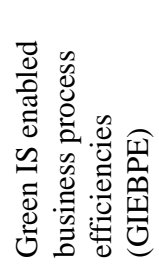 & 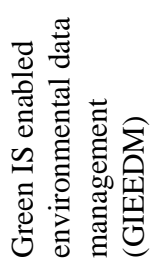 & 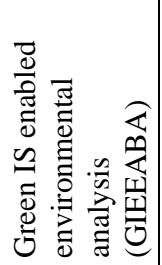 & 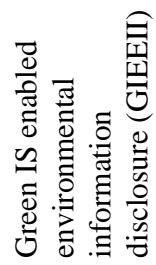 \\
\hline
\end{tabular}


Green IS Management Framework Corroboration and Verification

\begin{tabular}{|c|c|c|c|c|c|c|}
\hline$\stackrel{\pi}{0}$ & $\stackrel{M}{\sim}$ & $\bar{n}$ & in & $\underset{\sim}{\stackrel{ \pm}{N}}$ & テ & $\underset{\infty}{\infty}$ \\
\hline 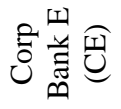 & $a$ & $\nabla$ & in & న & $\simeq$ & $\infty$ \\
\hline 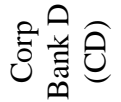 & $m$ & 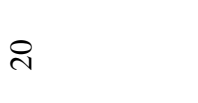 & 이 & กี & $m$ & $\stackrel{\infty}{=}$ \\
\hline 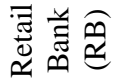 & $\stackrel{\sim}{\text { N }}$ & 0 & 6 & $\stackrel{\mathcal{J}}{\mathcal{V}}$ & 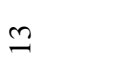 & 6 \\
\hline 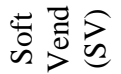 & $\infty$ & 으 & $\nabla$ & $r$ & $m$ & శ̊ \\
\hline ప & - & - & $N$ & $m$ & $N$ & 于 \\
\hline 仓ี & $N$ & 0 & - & $\underline{\sigma}$ & $\forall$ & $\stackrel{\sim}{+}$ \\
\hline 过光 & $\simeq$ & $r$ & $r$ & $\infty$ & - & $\infty$ \\
\hline 导光芯 & $\infty$ & $a$ & $\simeq$ & mे & $a$ & $\hat{m}$ \\
\hline 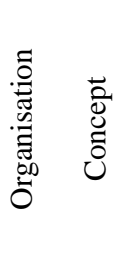 & 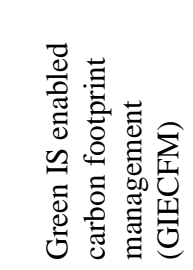 & 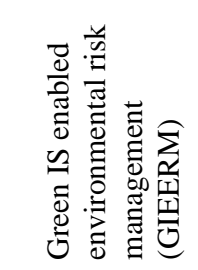 & 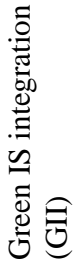 & 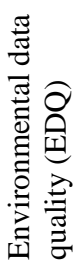 & 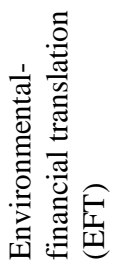 & 䒕 \\
\hline
\end{tabular}


The contingency table data was input into the statistical software application called SPSS (IBM SPSS, n.d.) producing descriptive statistical analyses for a basic level of insight into the data. In order to gain deeper insight for corroborating the framework, it was appropriate to perform correspondence analysis based on the same contingency table data, also using SPSS. Figure 1 below describes the correspondence analysis output, namely the perceptual map that is analysed in the following paragraphs. The axes are numerical scales to illustrate relative distances from the centroid to each profile point (Remenyi 1992).

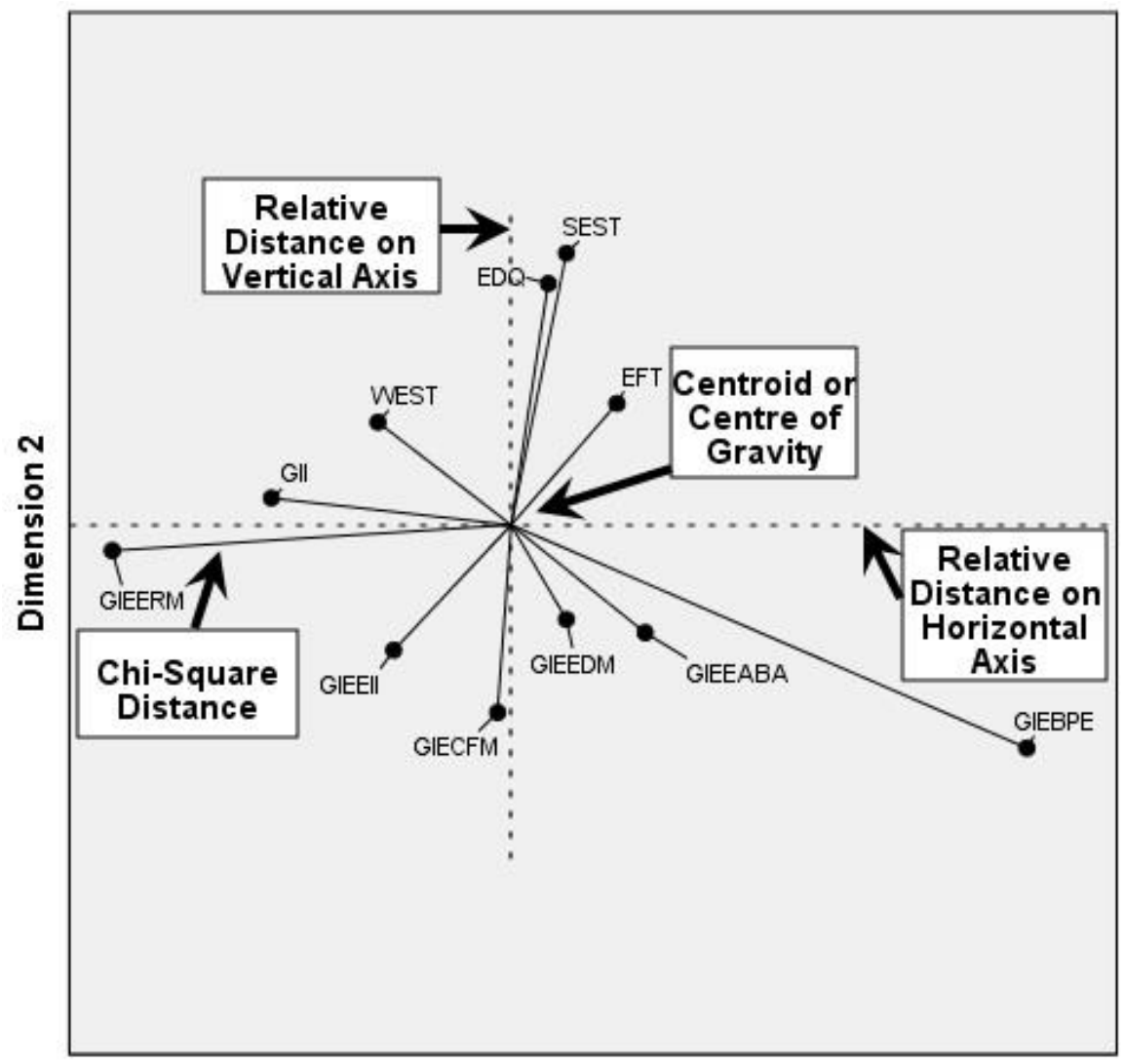

Dimension 1

Figure 1: Correspondence analysis perceptual map description 
Before analysing the perceptual map, there were a number of important outputs to consider, relating to the selected number of dimensions of the perceptual map and the related inertias. Table 2 below shows how the total inertia is decomposed along the maximum number of dimensions based on the contingency table data. The first dimension accounted for $32.1 \%$ of the total inertia and the second dimension for another $26.4 \%$ of the total inertia. Therefore, displaying two dimensions accounted for $58.4 \%$ of the total inertia or almost two-thirds, and yielded useful analysis. Therefore, the analysis proceeded with a two-dimensional perceptual map.

\begin{tabular}{|l|r|r|}
\hline \multirow{2}{*}{ Dimension } & \multicolumn{2}{|c|}{ Proportion of Inertia } \\
\cline { 2 - 3 } & Accounted for & Cumulative \\
\hline 1 & .321 & .321 \\
2 & .264 & .584 \\
3 & .206 & .790 \\
4 & .119 & .910 \\
5 & .051 & .960 \\
6 & .035 & .995 \\
7 & .005 & 1.000 \\
Total & 1.000 & 1.000 \\
\hline
\end{tabular}

Table 2: Total inertia per dimension

Furthermore, analyses of how each concept contributed to the inertia of the first two dimensions and how the first two dimensions contributed to the inertia of each concept determined that the concepts were suitably represented in the first two dimensions, which further supported proceeding with a twodimensional perceptual map. Similarly, analyses of how each organisation contributed to the inertia of the first two dimensions and how the first two dimensions contributed to the inertia of each organisation determined that the organisations were suitably represented in the first two dimensions, which also supported proceeding with a two-dimensional perceptual map.

Figure 2 below presents the two-dimensional perceptual map for the concepts. The map shows a general horizontal axis split, where the top rectangle grouping incorporates the concepts weak environmental sustainability transformation (WEST), strong environmental sustainability 
transformation (SEST), Green IS integration (GII), environmental data quality (EDQ), and environmental-financial translation (EFT). These are the framework concepts relating to environmental sustainability transformation and the moderating concepts, suggesting that the moderating concepts are associated with environmental sustainability transformation.

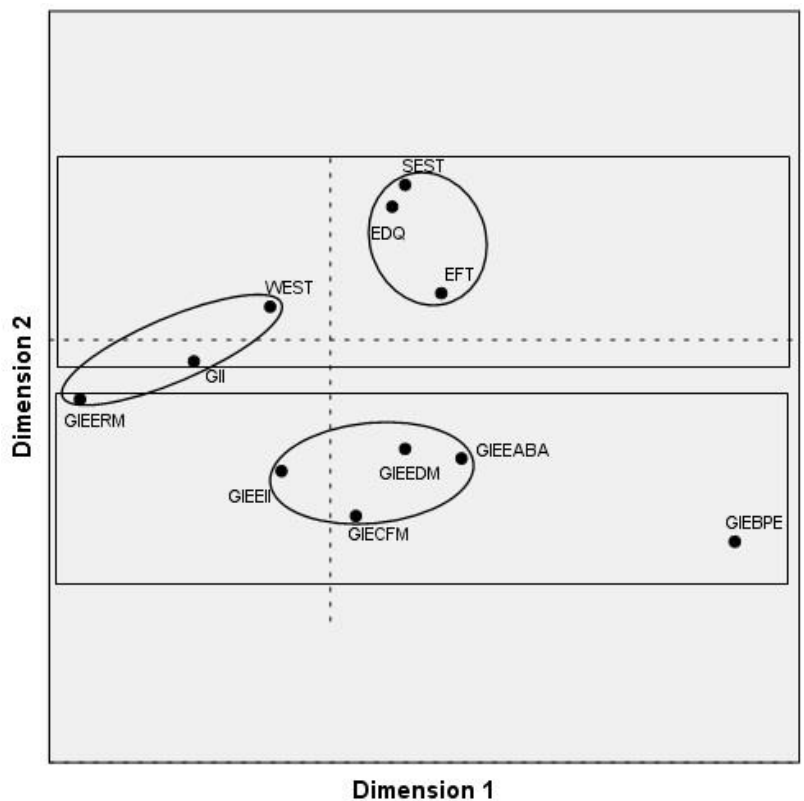

Figure 2: Concept perceptual map

The bottom rectangle grouping incorporates the Green IS enabled aspects, namely environmental risk management (GIEERM), environmental information disclosure (GIEEII), environmental data management (GIEEDM), environmental analysis (GIEEABA), carbon footprint management (GIECFM), and business process efficiencies (GIEBPE). This suggests that there is a Green IS enabling association among them. Notably, business process efficiencies (GIEBPE) is away from all the other aspects to the right, which supports its unique and implicit Green IS relation. In addition, environmental risk management (GIEERM) is away from all the other aspects to the left, supporting its unique external focus. Furthermore, the large distance between environmental risk management (GIEERM) and business process 
efficiencies (GIEBPE) illustrates the uniqueness and dissimilarity between these concepts, being externally and environmental sustainability focused and internally and cost efficiency focused, respectively.

In addition, there are a number of closely grouped clusters. Strong environmental sustainability transformation (SEST), environmental data quality (EDQ), and environmental-financial translation (EFT) are one such cluster, suggesting that environmental data quality (EDQ) and environmentalfinancial translation (EFT) are particularly associated with strong environmental sustainability transformation (SEST).

Another cluster is environmental risk management (GIEERM), Green IS integration (GII), and weak environmental sustainability transformation (WEST), which suggest that the current form of environmental sustainability transformation, namely weak environmental sustainability transformation (WEST), is associated with environmental risk management (GIEERM) and moderated by Green IS integration (GII). This provides support that Green IS integration (GII) was necessary to leverage Green IS enabled environmental risk management (GIEERM) for weak environmental sustainability transformation (WEST).

The third cluster is environmental information disclosure (GIEEII), environmental data management (GIEEDM), environmental analysis (GIEEABA), and carbon footprint management (GIECFM), supporting the framework depiction where carbon footprint management (GIECFM) is closely associated with, and in many cases, subsumes these aspects.

Figure 3 below presents the two-dimensional perceptual map for the organisations. The map shows that the organisations are widely spread, indicating that they had unique characteristics, even though many were in the same banking industry. This supports the adequacy of the sample by showing that the data accounts for wide variety across the industry. Nevertheless, there are a number of closely grouped clusters. These clusters are corporate bank D and the industry body; corporate banks E and C; and the software vendor and corporate bank B. The clustered organisations indicate commonality between these organisations. It is apparent that the industry body had comparable views to one of the corporate banks, as did the software vendor; this provides support that these non-corporate banking organisations understood the corporate banking aspects relating to the study and were relevant to the study. The retail bank stands out on its own away from the other organisations, which supports 
its role as a negative sampling instance, because such a bank does not provide financing to organisations throughout the economy.

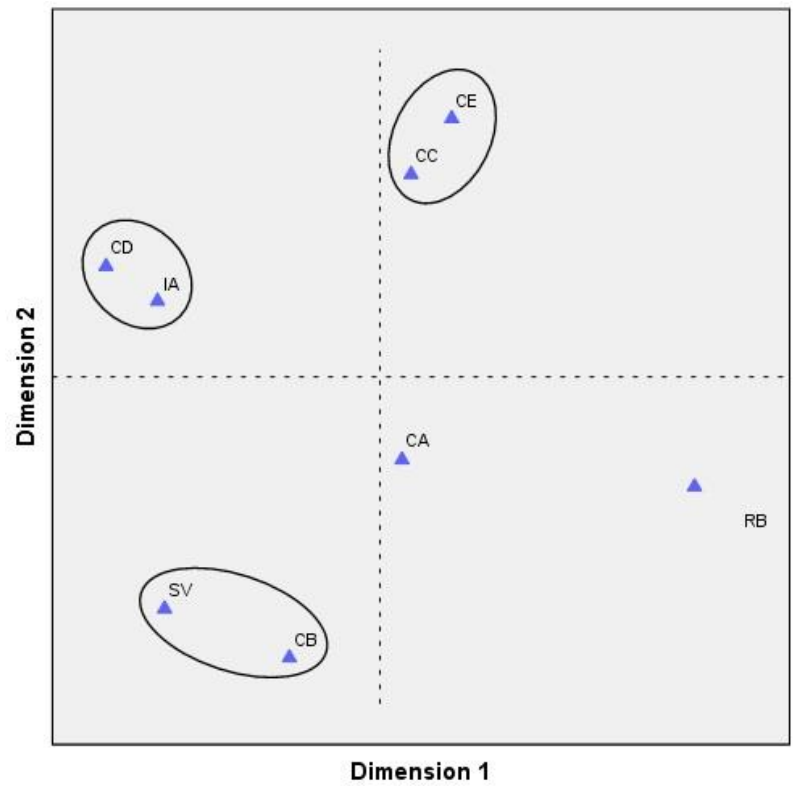

Figure 3: Organisation perceptual map

Figure 4 below presents the two-dimensional perceptual map for both the concepts and organisations. The map presents three general clusters of concepts and organisations. The first cluster shows that corporate bank D and the industry body are associated with environmental risk management (GIEERM), Green IS integration (GII), and weak environmental sustainability transformation (WEST), exposing their focus on Green IS integration (GII) to leverage environmental risk management (GIEERM) for weak environmental sustainability transformation (WEST).

The second cluster illustrates that corporate banks $\mathrm{C}$ and $\mathrm{E}$ are associated with strong environmental sustainability transformation (SEST), environmental data quality (EDQ), and environmental-financial translation (EFT); that is, they are focused on environmental data quality (EDQ) and environmental-financial translation (EFT), and a basic level of strong environmental sustainability transformation (SEST), although corporate bank 
$\mathrm{C}$ is further away from strong environmental sustainability transformation (SEST).

The third cluster demonstrates that corporate banks $\mathrm{A}$ and $\mathrm{B}$, the software vendor, and the retail bank are associated with environmental information disclosure (GIEEII), environmental data management (GIEEDM), environmental analysis (GIEEABA), and carbon footprint management (GIECFM). Indeed, within this cluster the software vendor's close proximity to environmental information disclosure (GIEEII) and carbon footprint management (GIECFM) is explained by their software offering that is focused on carbon footprint management and related reporting. In addition, the software vendor is away from environmental data management (GIEEDM) and environmental analysis (GIEEABA). Notably, the retail bank is the closest to business process efficiencies (GIEBPE), which is one of their main focuses.

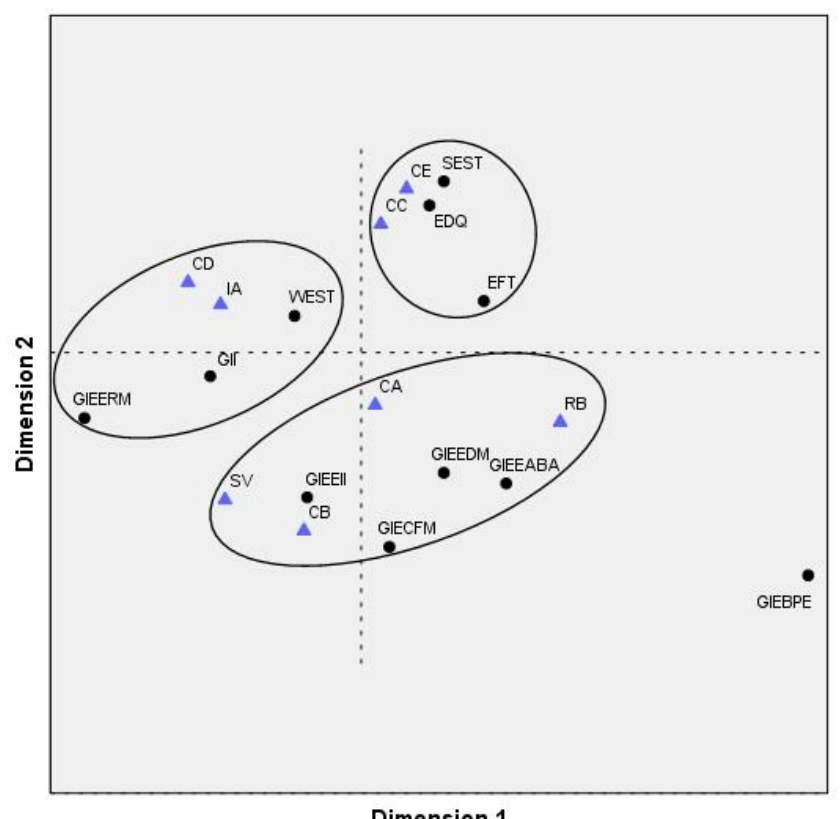

Figure 4: Concept and organisation perceptual map 


\section{Focus Group}

The aim of the focus group method was to provide conclusive evidence from knowledgeable and professional experts in the field for verification of the initially developed and corroborated framework. Interaction effects were evident during the focus group session, especially in terms of group learning. On several occasions, an initial opinion was expressed and as participants joined that particular discussion, the initial opinion was developed into a more complete group opinion. Furthermore, initial opinions seemed to become more considered, in terms of the overall group discussion, as the discussions unfolded and other perspectives, experience, and information were provided.

The focus group did not result in significant changes to and provided support for the framework's core concepts and their interrelationships (Howard 2014). The modifications to the framework as required by the focus group related mostly to contextual detail additions to enhance its usefulness for practitioners. In addition, there was a terminology change request relating to the enabling capability of Green IS aspect called carbon footprint management. The group indicated that ecological footprint management provided a more holistic concept for application to all organisations. Therefore, this concept's name was changed to carbon (and ecological) footprint management. Given that carbon footprint management is still a priority in the banking industry and prevalent in comparison to the other ecological footprint items, the term carbon footprint management remained central to this aspect. Thus, with confirmation of and without changes to the framework's core concepts and their interrelationships, the framework was verified and was regarded as relevant through expert evaluation, which is competent research evidence.

\section{Member Checking}

The aim of the member checking was to provide credibility to the study and further verify the framework. The member checking provided support for the framework's core concepts and their interrelationships and did not significantly change it. The modifications to the framework, as required by the members, related to more contextual detail to enhance its usefulness for practitioners. The main feedback that was received was that the framework would be useful in practice for its purpose and that it conceptualised the role of Green IS in the domain. Thus, the framework was regarded as credible and 
the framework's core concepts and their interrelationships were regarded as verified.

\section{The Verified Green IS Management Framework}

The verified Green IS management framework, which has been corroborated using content and correspondence analysis and verified through focus group analysis and member checking, is presented below in Figure 5.

\section{Conclusion}

The paper has addressed the research problem of an unverified framework. The paper met the research objectives and answered the research questions. The paper demonstrated the quantitative corroboration of the Green Information Systems (Green IS) management framework, which comprises the enabling capabilities of Green IS, the moderating concepts, and their relationships to environmental sustainability. In addition, the paper demonstrated the framework's verification by detailing the focus group method and member checking. The achievement of these objectives establishes that the framework successfully captured the essential Green IS concepts and interrelationships to be relevant for environmental sustainability and that it was credible, relevant, and an original contribution to the academic body of knowledge.

From a methodological perspective, the study provides research design insights by detailing research design choices and rationale. This provides value for academics by demonstrating the value of such quantitative analysis for enhancing qualitative framework development. In addition, the suitability and application of the focus group method for framework verification and relevance is demonstrated, as is the use of member checking to provide credibility, relevance, and verification.

This provided triangulation that strengthened the research findings, improved the accuracy of inferences, and increased credibility. Furthermore, it mitigated the problem of inherent bias that exists in any one particular approach, mitigated the limitations of a single research approach, benefited from different epistemological perspectives, had greater applicability to the complex organisational contexts, and made a more significant contribution to scholarly and practical knowledge. 
Grant R. Howard, Sam Lubbe, Magda Huisman \& Rembrandt Klopper

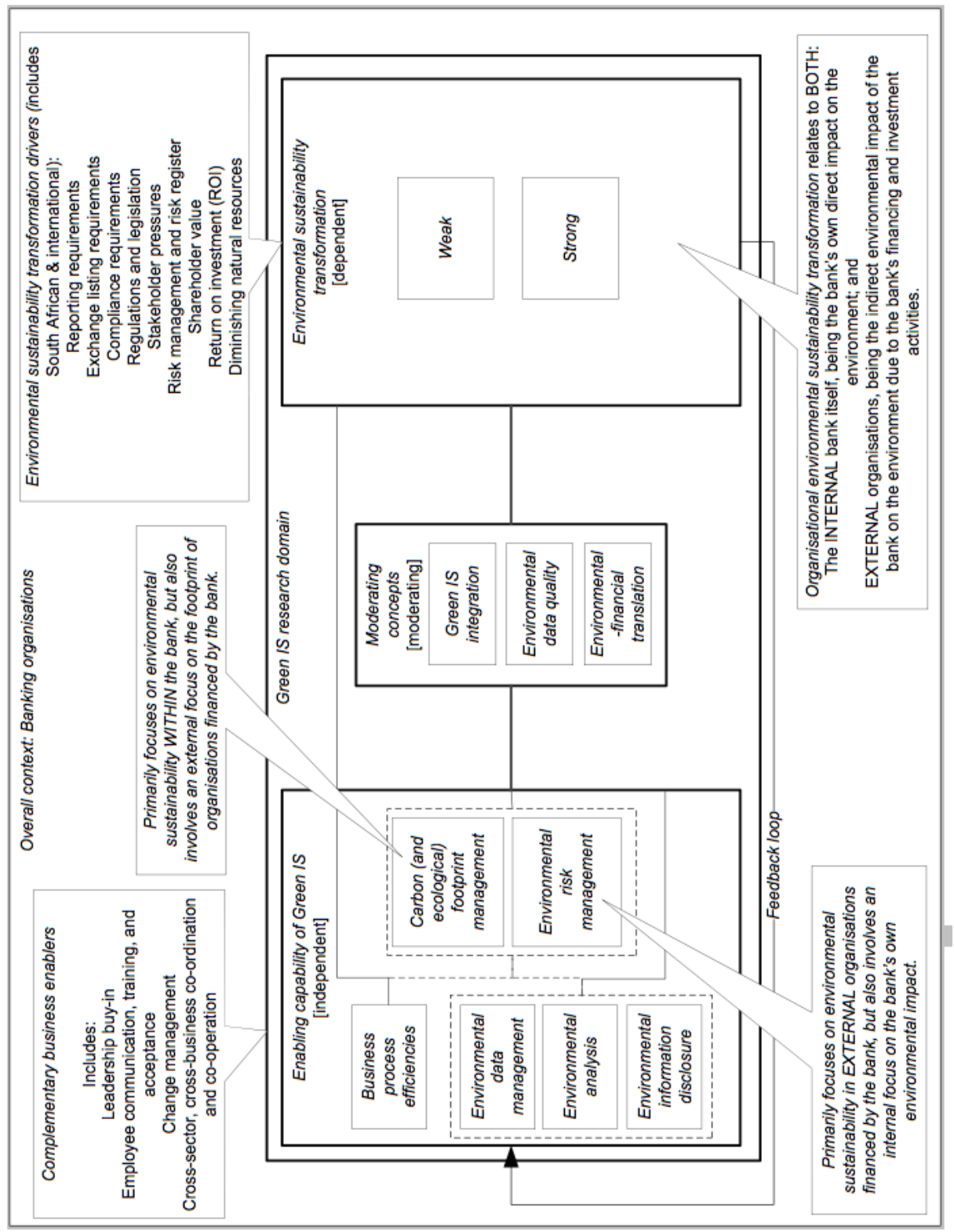

Figure 5: The Verified Green IS Management Framework 
Addressing environmental resource depletion and degradation is a permanent business reality for organisations; it is a challenge and an opportunity. The Green IS framework depicts how IS can be leveraged to further environmental sustainability. The framework highlights the enabling capabilities of Green IS that facilitate environmental sustainability, both within the banking organisations and in other varied organisations throughout the economy through their business interactions with the banking organisations. The framework also emphasises three key concepts that moderate how the enabling capabilities of Green IS facilitate environmental sustainability. Attention to these three moderating concepts is vital for furthering environmental sustainability and the framework provides management with a handle on these vital concepts.

Nonetheless, there are numerous future research opportunities. The South African economy is influenced by numerous international banks, not just SA banks, via their SA branches, and these potentially provide opportunities for new data to elaborate on and extend the Green IS framework, both locally and internationally. Additionally, the entire SA financial services sector, not just banking, may potentially provide new data for elaborating on and extending the Green IS framework.

Another interesting avenue for research may be extending the Green IS framework to organisations in other industries, apart from financial services. Such extension will raise the theoretical abstraction of the framework as well as its relevance and usefulness in practice. It may require adapting the financing aspect of the framework to supply chain aspects.

\section{References}

Allenby, B.R., W.D. Compton \& D.J. Richards 2001. Information Systems and the Environment: Overview and Perspectives. In Richards, D.J., B.R. Allenby \& W.D. Compton (eds.): Information Systems and the Environment. Washington, D.C: National Academy Press.

Aral, S., E. Brynjolfsson \& M. van Alstyne 2012. Information, Technology, and Information Worker Productivity. Information Systems Research 23,3Part-2: 849 - 867.

Besson, P. \& F. Rowe 2012. Strategizing Information Systems-Enabled Organizational Transformation: A Transdisciplinary Review and New 
Grant R. Howard, Sam Lubbe, Magda Huisman \& Rembrandt Klopper

Directions. Journal of Strategic Information Systems 21, 2: 103 - 124.

https://doi.org/10.1016/j.jsis.2012.05.001

Bhattacherjee, A. \& G. Premkumar 2004. Understanding Changes in Belief and Attitude toward Information Technology Usage: A Theoretical Model and Longitudinal Test. MIS Quarterly 28, 2: 229 - 254.

https://doi.org/10.2307/25148634

Bryman, A. \& E. Bell 2011. Business Research Methods. $3^{\text {rd }}$ Edition. New York: Oxford University Press.

Carey, M.A. \& J. Asbury 2012. Focus Group Research. New York: Left Coast Press, Inc.

Ceci, F. \& D. Iubatti 2012. Personal Relationships and Innovation Diffusion in

SME Networks: A Content Analysis Approach. Research Policy 41,3: 565 $-579$.

https://doi.org/10.1016/j.respol.2011.10.003

Chen, J.L. 2012. The Synergistic Effects of IT-Enabled Resources on

Organizational Capabilities and Firm Performance. Information \& Management 49,3 - 4: 142 - 150.

Curry, E., S. Hasan, U. ul Hassan, M. Herstand \& S. O'Riain 2011. An Entitycentric Approach to Green Information Systems. Proceedings of the $19^{\text {th }}$ European Conference on Information Systems (ECIS). Helsinki, Finland.

Dao, V., I. Langella \& J. Carbo 2011. From Green to Sustainability: Information Technology and an Integrated Sustainability Framework. Journal of Strategic Information Systems 20,1: 63 - 79.

https://doi.org/10.1016/j.jsis.2011.01.002

Dietz, S. \& E. Neumayer 2007. Weak and Strong Sustainability in the SEEA:

Concepts and Measurement. Ecological Economics 61,4: 617 - 626.

https://doi.org/10.1016/j.ecolecon.2006.09.007

Ekins, P., S. Simon, L. Deutsch, C. Folke \& R. de Groot 2003. A Framework for the Practical Application of the Concepts of Critical Natural Capital and Strong Sustainability. Ecological Economics 44: 165 - 185.

https://doi.org/10.1016/S0921-8009(02)00272-0

Elliot, S. 2011. Transdisciplinary Perspectives on Environmental Sustainability: A Resource Base and Framework for IT-Enabled Business Transformation. MIS Quarterly 35,1: 197 - 236.

https://doi.org/10.2307/23043495

EP 2012. The Equator Principles III - Draft \& Summary of Key Changes. UK:

The Equator Principles (EP) Association. Available at: 
http://www.equator-principles.com/resources/EPIII_PACKAGE.pdf. (Accessed on 06 November 2012.)

Goodland, R. 1995. The Concept of Environmental Sustainability. Annual Review of Ecology and Systematics 26: 1 - 24.

https://doi.org/10.1146/annurev.es.26.110195.000245

Goodland, R. \& H. Daly 1996. Environmental Sustainability: Universal and Non-Negotiable. Ecological Applications 6,4: 1002 - 1017.

https://doi.org/10.2307/2269583

Greenacre, M. 2006. Tying up the Loose Ends in Simple Correspondence Analysis: Economics Working Papers 940. Barcelona: Department of Economics and Business, Universitat Pompeu Fabra. Available at:

https://repositori.upf.edu/bitstream/handle/10230/1144/940.pdf?sequenc=

1 (Accessed on 06 November 2013.)

Greenacre, M. \& P. Lewi 2009. Distributional Equivalence and Subcompositional Coherence in the Analysis of Compositional Data, Contingency Tables and Ratio-scale Measurements. Journal of Classification 26,1: 29 - 54.

https://doi.org/10.1007/s00357-009-9027-y

Hoffman, A.J. 2010. Climate Change as a Cultural and Behavioral Issue: Addressing Barriers and Implementing Solutions. Organizational Dynamics 39: 295 - 305.

https://doi.org/10.1016/j.orgdyn.2010.07.005

Holmström, J., L. Mathiassen, J. Sandberg \& H. Wimelius 2010. Green IS: Steps Towards a Research Agenda. In Holmström, J., M. Wiberg \& A. Lund (eds): Industrial Informatics Design, Use and Innovation: Perspectives and Services. Hershey: IGI Global.

https://doi.org/10.4018/978-1-61520-692-6 https://doi.org/10.4018/978-1-61520-692-6.ch014

Howard, G. 2014. Explicating the Enabling Capabilities of Green IS: A Management Framework for South African Banks, PhD, NWU Mafikeng, SA. Available at:

http://hdl.handle.net/10394/18005 (Accessed on 16 January 2019.)"

Howard, G.R. \& S. Lubbe 2012. Synthesis of Green IS Frameworks for Achieving Strong Environmental Sustainability in Organisations. Proceedings of the 2012 Conference of the S.A. Institute for Computer Scientists and Information Technologists (SAICSIT). Centurion, South Africa. https://doi.org/10.1145/2389836.2389873 
Grant R. Howard, Sam Lubbe, Magda Huisman \& Rembrandt Klopper

IBM SPSS n.d. SPSS Software. Available at:

https://www.ibm.com/analytics/spss-statistics-software (Accessed on 19 September 2012.)

Jenkin, T.A., J. Webster \& L. McShane 2011. An Agenda for 'Green' Information Technology and Systems Research. Information and Organization 21,1: 17 - 40. https://doi.org/10.1016/j.infoandorg.2010.09.003

Krefting, L. 1991. Rigor in Qualitative Research: The Assessment of Trustworthiness. The American Journal of Occupational Therapy 45,3: $214-222$.

https://doi.org/10.5014/ajot.45.3.214

Kuo, B.N. 2010. Organizational Green IT: It Seems the Bottom Line Rules. Proceedings of the 16th Americas Conference on Information Systems (AMCIS). Lima, Peru.

Laine, M. 2010. Towards Sustaining the Status Quo: Business Talk of Sustainability in Finnish Corporate Disclosures 1987-2005. European Accounting Review 19,2: 247 - 274.

https://doi.org/10.1080/09638180903136258

Lee, A.S. 2004. Thinking about Social Theory and Philosophy for Information

Systems. In Mingers, J. \& L. Willcocks (eds): Social Theory and Philosophy for Information Systems. Chichester: John Wiley \& Sons.

Lee, B. 1996. Correspondence Analysis. In Young, F.W. (ed): ViSta: The Visual Statistics System. $2^{\text {nd }}$ Edition. Chapel Hill: L.L.Thursone Psychometric Laboratory, University of North Carolina. Available at: http://sunsite.csd.univie.ac.at/ViSta/vista-frames/pdf/chap11.pdf

(Accessed on 22 October 2013.)

Manzini, F., J. Islas \& P. Macías 2011. Model for Evaluating the Environmental Sustainability of Energy Projects. Technological Forecasting and Social Change 78: 931 - 944.

https://doi.org/10.1016/j.techfore.2011.01.012

Meacham, J., L. Toms, K.W. Green Jr \& V.S. Bhadauria 2013. Impact of Information Sharing and Green Information Systems. Management Research Review 36,5: 478 - 494.

https://doi.org/10.1108/01409171311327244

Melville, N.P. 2010. Information Systems Innovation for Environmental Sustainability. MIS Quarterly 34,1: 1 - 21.

https://doi.org/10.2307/20721412 
Mithas, S., N. Ramasubbu \& V. Sambamurthy 2011. How Information Management Capability Influences Firm Performance. MIS Quarterly 35,1: 237 $-256$.

https://doi.org/10.2307/23043496

Molla, A., S. Pittayachawan \& B. Corbitt 2009. Green IT Diffusion: An International Comparison. Melbourne: School of Business Information Technology, RMIT University. Available at:

http://works.bepress.com/siddhi/19/ (Accessed on 08 November 2017.)

Murugesan, S. 2008. Harnessing Green IT: Principles and Practices. IT Professional Magazine 10,1: 24 - 33.

https://doi.org/10.1109/MITP.2008.10

Nagpaul, P.S. 1999. Guide to Advanced Data Analysis Using IDAMS Software.

New Delhi: UNESCO. Available at:

http://www.unesco.org/webworld/idams/advguide/TOC.htm/

(Accessed on 04 November 2013.)

Nenadic, O. \& M. Greenacre 2007. Correspondence Analysis in R, with Twoand Three-dimensional Graphics: The CA Package. Journal of Statistical Software 20,3: 1 - 13.

O'hEocha, C., X. Wang \& K. Conboy 2012. The Use of Focus Groups in Complex and Pressurised IS Studies and Evaluation using Klein \& Myers Principles for Interpretive Research. Information Systems Journal 22,3: $235-256$.

Perrow, C. 1997. Organizing for Environmental Destruction. Organization \& Environment 10,1: 66 - 72.

https://doi.org/10.1177/0921810697101009

Phillips, D. 1995. Correspondence Analysis. Social Research Update 7: 1 - 8.

Pitt, L.F., M. Parent, I. Junglas, A. Chan \& S. Spyropoulou 2011. Integrating the Smartphone into a Sound Environmental Information Systems Strategy: Principles, Practices and a Research Agenda. Journal of Strategic Information Systems 20,1: 27 - 37.

https://doi.org/10.1016/j.jsis.2010.09.005

Remenyi, D. 1992. Researching Information Systems: Data Analysis Methodology using Content and Correspondence Analysis. Journal of Information Technology 7,2: 75 - 90.

https://doi.org/10.1177/026839629200700203

https://doi.org/10.1057/jit.1992.12

Roberts, N. \& V. Grover 2012. Leveraging Information Technology Infra- 
Grant R. Howard, Sam Lubbe, Magda Huisman \& Rembrandt Klopper

structure to Facilitate a Firm's Customer Agility and Competitive Activity: An Empirical Investigation. Journal of Management Information Systems 28,4: 231 - 269.

https://doi.org/10.2753/MIS0742-1222280409

Rosemann, M. \& I. Vessey 2008. Toward Improving the Relevance of Information Systems Research to Practice: The Role of Applicability Checks. MIS Quarterly 32,1: 1 - 22.

https://doi.org/10.2307/25148826

Shenton, A.K. 2004. Strategies for Ensuring Trustworthiness in Qualitative Research Projects. Education for Information 22,2: 63 - 75.

https://doi.org/10.3233/EFI-2004-22201

Soni, G. \& R. Kodali 2013. A Critical Review of Supply Chain Management

Frameworks: Proposed Framework. Benchmarking: An International Journal 20,2: 263 - 298.

Tambe, P. \& L.M. Hitt 2012. The Productivity of Information Technology Investments: New Evidence from IT Labor Data. Information Systems Research 23,3-Part-1: 599 - 617.

The Climate Group 2008. SMART 2020: Enabling the Low Carbon Economy in the Information Age. The Climate Group on Behalf of the Global eSustainability Initiative (GeSI). Available at:

http://www.gesi.org/LinkClick.aspx?fileticket=tbp5WRTHUoY\%3D

(Accessed on 21 October 2011.)

Tremblay, M.C., A.R. Hevner \& D.J. Berndt 2010. Focus Groups for Artifact

Refinement and Evaluation in Design Research. Communications of the Association for Information Systems 26,1: 599 - 618.

https://doi.org/10.17705/1CAIS.02627

UNEP 2011. Annual Report 2010. Nairobi: United Nations Environment Programme (UNEP). Available at:

http://www.unep.org/annualreport/2010/pdfs/UNEP-AR-2010-FULL-

REPORT.pdf (Accessed on 23 September 2011.)

Volkoff, O., S. Bertels \& D. Papania 2011. The Strategic Role of Information

Systems in Supporting Sustainability. Proceedings of the $17^{\text {th }}$ Americas

Conference on Information Systems (AMCIS). Detroit, USA.

Watson, R.T., M.C. Boudreau \& A.J. Chen 2010. Information Systems and Environmentally Sustainable Development: Energy Informatics and New Directions for the IS Community. MIS Quarterly 34,1: 23 - 38. https://doi.org/10.2307/20721413 
Watson, R.T., M.C. Boudreau, A.J. Chen \& M.H. Huber 2008. Green IS: Building Sustainable Business Practices. In Watson, R.T. (ed.): Information Systems. Athens: Global Text Project.

Watson, R.T., M.C. Boudreau, S. Li \& J. Levis 2010. Telematics at UPS: En Route to Energy Informatics. MIS Quarterly Executive 9,1: 1 - 11.

Watson, R.T. \& M. Boudreau 2011. Energy Informatics. Athens: Green ePress. Watson, R.T., J. Corbett, M.C. Boudreau \& J. Webster 2012. An Information Strategy for Environmental Sustainability. Communications of the ACM 55,7: 28 - 30 .

https://doi.org/10.1145/2209249.2209261

Grant R. Howard

School of Computing University of South Africa (UNISA)

Florida, South Africa

howargr@unisa.ac.za

Sam Lubbe Milpark Business School Johannesburg sam.lubbe@gmail.com

Magda Huisman School of Computer, Statistical and Mathematical Sciences North-West University (NWU) Potchefstroom, South Africa magda.huisman@nwu.ac.za

Rembrandt Klopper Department of Communication Science University of Zululand KwaDlangezwa, South Africa rklopper@gmail.com 